\title{
Plumb Line Variations (PLV) at China and Their Relation with Earthquakes and Underground Materials Changes
}

\author{
Yongzhang Yang ${ }^{1,2}$, Jinsong Ping ${ }^{1,2}$, Zhengxin $\mathrm{Li}^{1,2}$ \\ ${ }^{1}$ National Astronomical Observatories, CAS, Beijing China \\ ${ }^{2}$ Shanghai Astronomical Observatory, CAS Shanghai China \\ Email: yzyang@shao.ac.cn
}

Received 2013

\begin{abstract}
Plumb line variations (PLV) of points at Tangshan and Midu during 1985-1998 are determined by using the 46 batch repeated gravity observations of the Beijing-Tangshan network and 32 batch repeated gravity observations of the West-Yunan network. As for Tangshan region, relation between underground matter change (UMC) and the PLV on ground are discussed and approach of determining the UMC by a derived regional PLV is found. The UMC before and after earthquake (1995.10.05, Mb 5.0) in Tangshan region, as an example, is studied, giving the location and depth of the mass center of underground disturbing body as well as its mass quantity.
\end{abstract}

Keywords: Plumb line Variations; Earthquake; Gravimetric Network; Underground Material Changes

\section{Introduction}

We know now that the "variations in the deflection of the vertical" (or plumb line variations, PLV, as follows) is a local phenomenon, they are different in different locations [1]. It is here to discuss them in the case of northern China.

There are only a few astrometric instruments in China, not enough to give a complete picture of the PLVs there. Fortunately, repeated observations of a gravimetric network in some regions (Figure 1 and Figure 4) can be used, from which the PLV within the region has been calculated [2].

\section{Plumb Line Variations (PLV) at Tangshan and Midu and Their Relation with Earthquakes}

\subsection{PLV at Tangshan and Its Relation to the Earthquakes Around ( $M$ > 4.0)}

Tangshan is a place where earthquakes happen frequently (Figure 1). The PLV, obtained by gravimetry technique, is shown in Figure 2, in which an annual term is also found [3]

The PLV time series is very close to its regression straight line, thus its component on the line is considered as a main one with which a comparison is made with the earthquakes around. It appears that earthquakes $(M>4.0)$ usually happen near the time when the PLV begins its opposite moving (Figure 3) [3,4].
It is clear that the PLV at Tangshan is detectable and is related to the earthquakes event around.

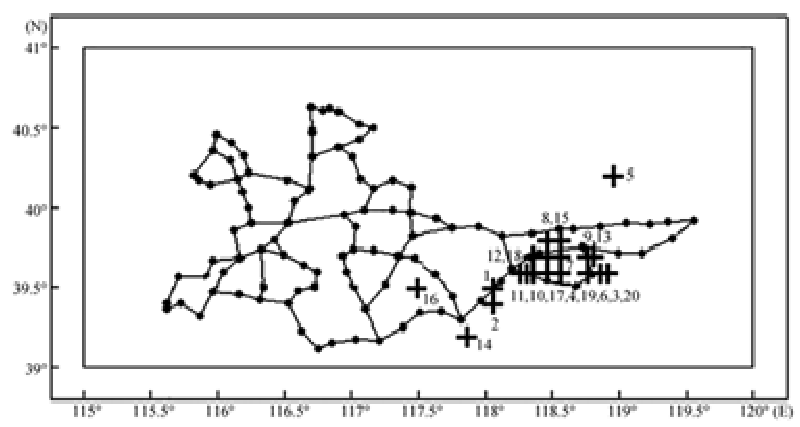

Figure 1. Gravity network in Northern China and the Earthquake $(M>4)$ in 1987-1998.
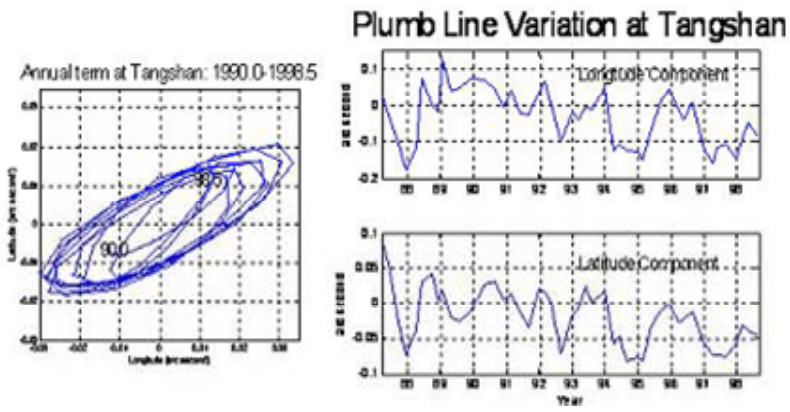

Figure 2. PLV time series (46 points: 1987.25 - 1998.67) at Tangshan and its annual term (left). 


\subsection{PLV at Midu and its Relation to the Earthquakes Around ( $M>5.0)$}

There is also a gravimetry network in West Yunnan, China (Figure 4). Similar work is done including the PLV at Midu (Figure 5) reduced by the observations of the network (Figure 6),

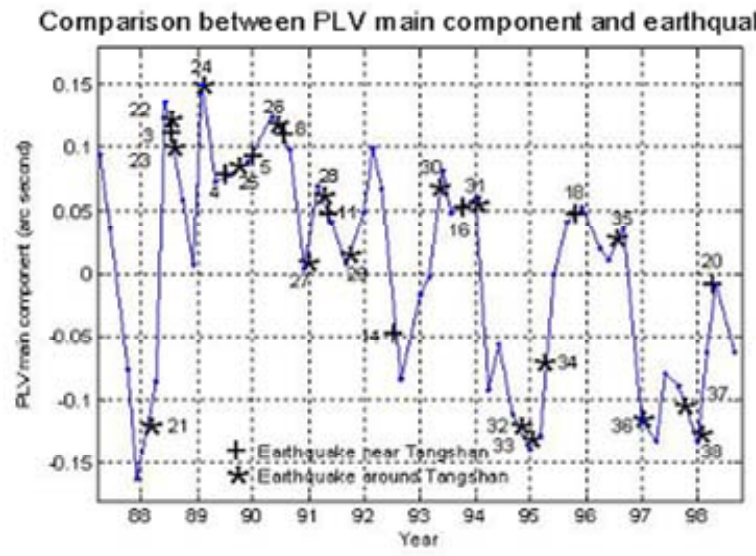

Figure 3. Relation between PLV main component at Tangshan and the earthquakes around.

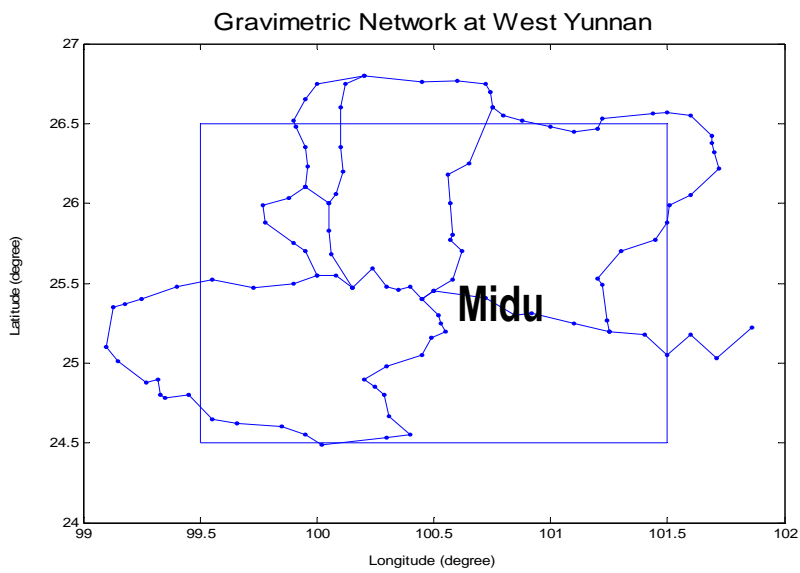

Figure 4. Gravimetry network at West Yunnan.

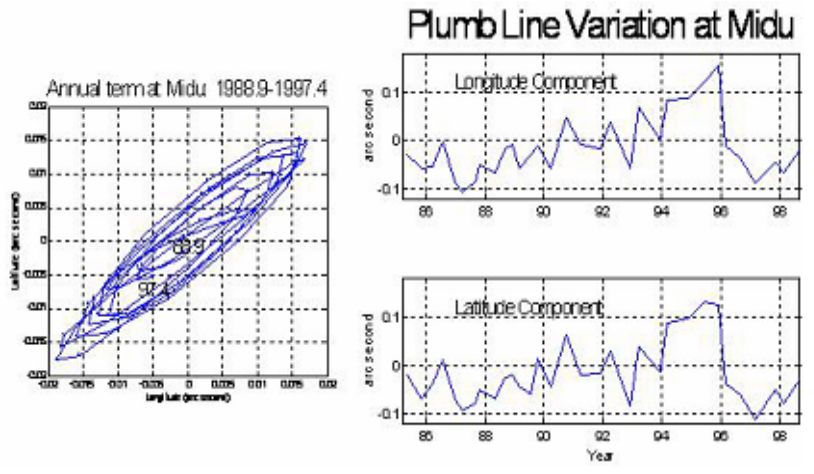

Figure 5. PLV time series (32 points: 1985.33 - 1998.75) at Midu and its annual term (left).
It is clear that the PLV at Midu is evident, as well as its relation with the around earthquakes.

\section{Relation between Plumb Line Variation in Tangshan Region and Underground Material Changes}

There are detectable PLVs in northern China, especially those derived before and after an Earthquake. Figure 2 shows one example, which is the PLVs related to the earthquake M5.0 (1995.76) [4].

In order to interpret Figure 7, a simulation is done in case of the existence of a disturbed body (point source) underground (Figure 8), from which one may say there

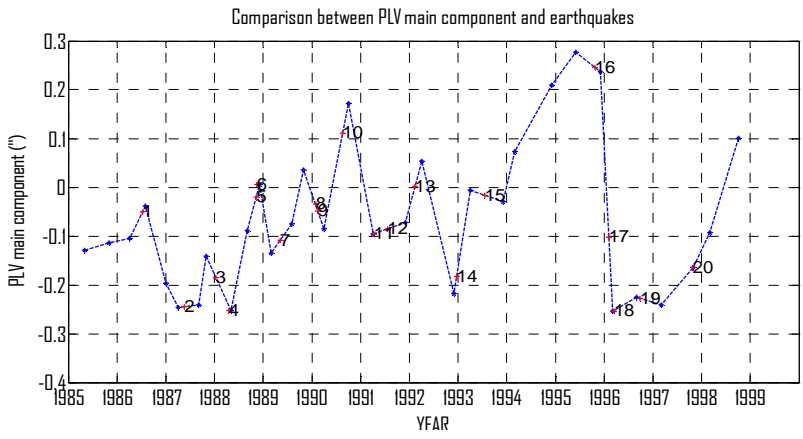

Figure 6. Relation between PLV main component at Midu and the earthquakes around.
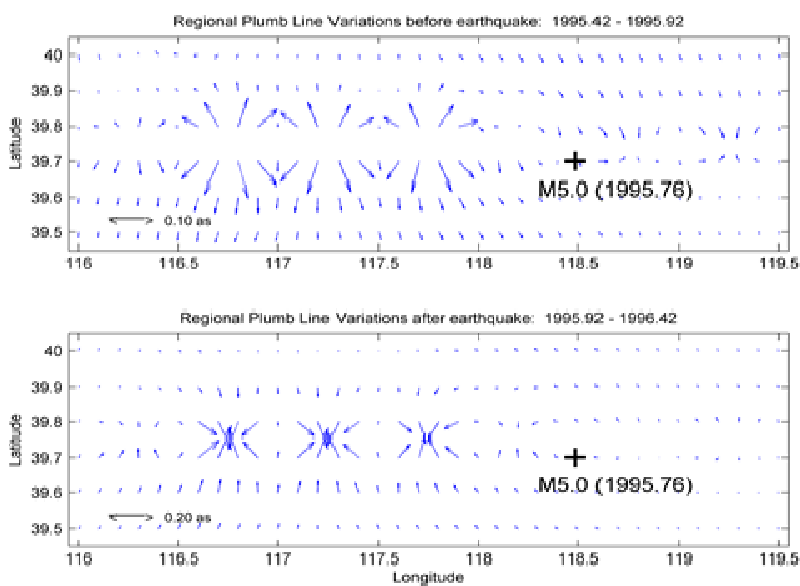

Figure 7. PLV before (upper part) and after (lower part) earthquake (unit: arc second (as)).
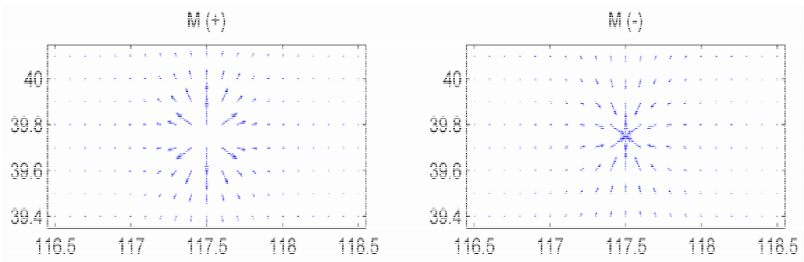

Figure 8. Simulation results of the PLVs on ground while there is an underground disturbed body (Mass: $M\left({ }^{+}\right)$positive; $M$ (-) negative). 
Table 1. Underground disturbing body determined related to the earthquake (1995.10.05; M5.0).

\begin{tabular}{|c|c|c|c|}
\hline \multirow{2}{*}{$\begin{array}{l}\text { Underground } \\
\text { disturbing body } \\
\text { Order of body } \\
\text { (W to E) }\end{array}$} & \multicolumn{3}{|c|}{$\begin{array}{l}\text { Time period before earthquake: } \\
1995.42-1995.92\end{array}$} \\
\hline & NO.1 & NO.2 & NO.3 \\
\hline $\begin{array}{l}\text { Longitude of mass } \\
\text { center }(\mathrm{E})\end{array}$ & 116.77 & 117.24 & 117.73 \\
\hline $\begin{array}{l}\text { Latitude of mass } \\
\text { center }(\mathrm{N})\end{array}$ & 39.76 & 39.76 & 39.76 \\
\hline $\begin{array}{l}\text { Depth of mass center } \\
\qquad(\mathrm{km})\end{array}$ & 6.75 & 6.20 & 6.85 \\
\hline $\begin{array}{c}\text { Mass quantity } \\
\text { (unit: } 1 \times 10 \text {; The } \\
\text { mass of Earth = 1) }\end{array}$ & 2.24 & 1.86 & 1.94 \\
\hline $\begin{array}{l}\text { Underground } \\
\text { disturbing body }\end{array}$ & \multicolumn{3}{|c|}{$\begin{array}{c}\text { Time period after earthquake: } \\
1995.92-1996.42 \\
\end{array}$} \\
\hline $\begin{array}{l}\text { Order of body } \\
\text { (W to E) }\end{array}$ & NO.1 & NO.2 & NO.3 \\
\hline $\begin{array}{l}\text { Longitude of mass } \\
\text { center }(\mathrm{E})\end{array}$ & 116.77 & 117.24 & 117.73 \\
\hline $\begin{array}{l}\text { Latitude of mass } \\
\text { center }(\mathrm{N})\end{array}$ & 39.76 & 39.76 & 39.76 \\
\hline $\begin{array}{l}\text { Depth of mass center } \\
\qquad(\mathrm{km})\end{array}$ & 6.65 & 6.50 & 7.15 \\
\hline $\begin{array}{c}\text { Mass quantity } \\
\text { (unit: } 1 \times 10 \text {; The } \\
\text { mass of Earth = 1) }\end{array}$ & 3.60 & 3.60 & 3.24 \\
\hline
\end{tabular}

are three underground disturbed bodies nearby the earthquake, and those derived after earthquake might be in pair, but in opposite sign, with their counter parts before earthquake.

The location, depth and mass of a body are calculated, listed in Table 1 [4].

It can be concluded that the PLVs detected in northern China are the observational signals of an underground disturbed body, with which parameters of the underground disturbed body can be calculated.

\section{REFERENCES}

[1] Z. X. Li, H. Li, Y. F. Li and Y. B. Han, "Non-tidal Variations in the Deflection of the Vertical at Beijing Observatory,” Journal of Geodesy, Vol. 78, No. 10, 2005, pp. 588-593.doi:10.1007/s00190-004-0421-2

[2] H. Li, G. Y. Fu and Z. X. Li, "Plumb Line Deflection Varied with Time Obtained by Repeated Gravimetry," Acta Seimologica, 2001, pp. 66-71.

[3] Z. X. Li and H. Li, "Earthquake-Related Gravity Field Changes at Beijing-Tangshan Gravimetric Network," Studia Geophysica et Geodaetica, Vol. 53, 2009, pp. 185-197. doi: 10.1007/s11200-009-0012-Z

[4] Z. X Li and H. Li, "Relation between Plumb Line Variation in Tangshan Region and Underground Material Changes. Acta Seimologica," Vol. 33, No. 6, 2011, pp. 817-827. 